\title{
Influence of territorial aggressiveness of ostrich males on egg production of companion female ostriches
}

\author{
H. Lambrechts ${ }^{1 \#}$, S.W.P. Cloete ${ }^{2}$, D. Swart ${ }^{3}$ and A.P. Pfister ${ }^{1}$ \\ ${ }^{1}$ Klein Karoo Agricultural Development Centre, PO Box 351, Oudtshoorn, $6620^{2}$ Elsenburg Agricultural Development \\ Institute, Private Bag X1, Elsenburg, 7607³ ARC-Grootfontein Small Stock Centre, Private Bag X529, Middelburg (EC), 5900 \\ "e-mail:heletl@wcape.agric.za \\ Introduction \\ Territorial behaviour in adult ostrich males, which is most often combined with aggressiveness, is observed \\ to a higher degree at the onset of and during breeding seasons. Territorial aggressiveness is most commonly \\ displayed towards other males, humans and even vehicles. During breeding seasons the shins of ostrich males \\ change in colour from a light pink to a crimson red. Displaying of territorial aggressiveness, together with the \\ change in colour of the shins, are most often used by ostrich farmers as an indication of the readiness of a male to \\ enter a breeding season. According to farming wisdom, a female will start laying once the male has made a nest \\ and this suggests that a female will start laying on certain behavioural cues of the male. This study investigated the \\ influence of territorial aggressiveness and shin colour of ostrich males on the reproductive performance of \\ accompanying females.
}

\section{Materials and Methods}

Ostrich breeding pairs ( $\mathrm{n}=136$ pairs) at the Klein Karoo Agricultural Development Centre, Oudtshoorn, were mated in camps of approximately 0.25 ha and received a balanced breeder diet at $2.5 \mathrm{~kg} / \mathrm{bird} / \mathrm{day}$, with free access to drinking water. The breeding season commenced on 24 May 1999 and ended on 29 February 2000. Each male was evaluated monthly in terms of shin colour and aggressiveness, using a scale of 0 to 10 for both aggressiveness and shin colour. An aggression score of 5 was awarded when males exhibited no territorial aggressiveness. An aggression score of 8 was awarded when males exhibited territorial aggressiveness. A score of 10 was awarded to males that exhibited extreme territorial aggressiveness towards the observers. A colour chart that was compiled by using commercial paint colour charts, were used to score shin colour. A score of 0 represented a white shin colour, with 5 being a pink shin colour and 10 a bright crimson red. Daily egg production was noted for each pair throughout the breeding season. Egg production performance (EPP) was calculated by using the following equation: [(Total number of eggs producedX2)/number of days in breeding season]\%.

\section{Results and Discussion}

Female companions of males that displayed territorial aggressiveness to a higher degree produced on average more eggs than companion females of males that exhibited territorial aggressiveness to a lesser extent throughout the breeding season. Female companions of males that were more territorially aggressive had on average an egg production performance of $30 \%$ and higher (Figure 1).

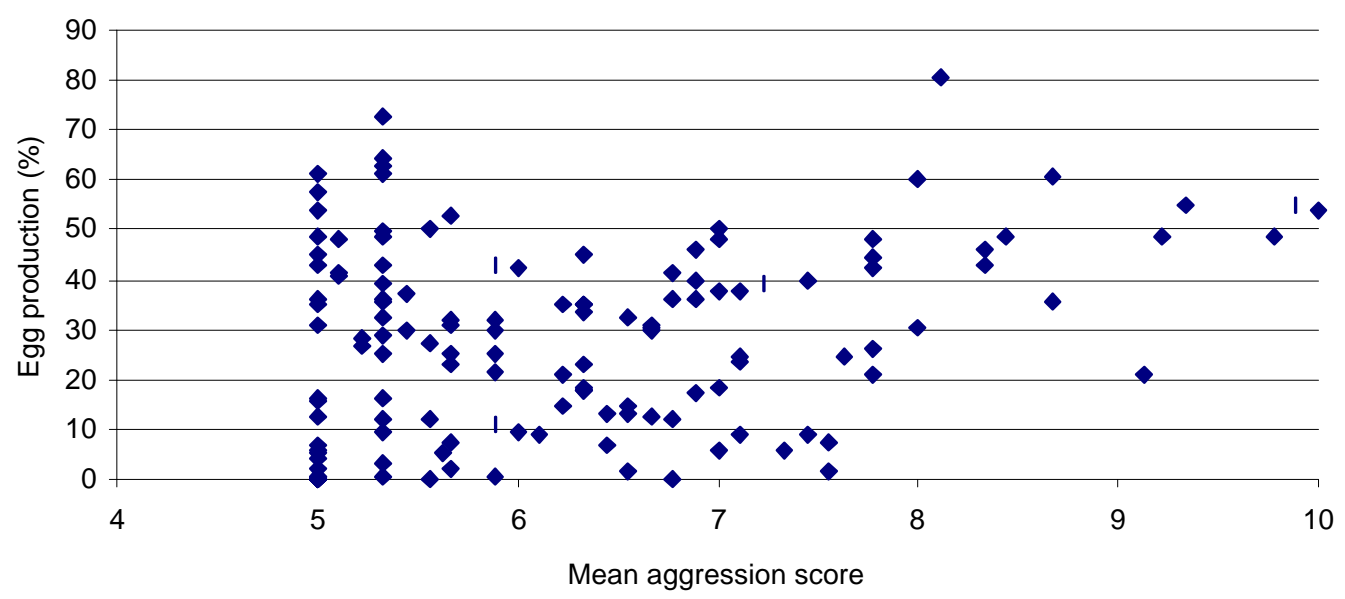

Figure 1 Egg production performance and mean territorial aggressiveness during the breeding season. 
Short paper and poster abstracts: $38^{\text {th }}$ Congress of the South African Society of Animal Science

It would thus seem that overt territorial aggressiveness of a male might have a positive stimulating influence on the reproductive performance of its companion female. A certain proportion of companion females of males that exhibited no territorial aggressiveness throughout the breeding season did, however, also produce well throughout the season (Figure 1). This would suggest that apart from the possible stimulating influence of the territorial aggressiveness of companion males, females might also be influenced by certain environmental and physiological factors that will ultimately determine her reproductive performance. Monthly means for shin colour increased $(\mathrm{P}<0.01)$ from $7.1 \pm 0.1$ in June 1999, to reach a maximum of $8.0 \pm 0.1$ during September (Figure 2). This was followed by a steady decline $(\mathrm{P}<0.01)$ to approximately $7.3 \pm 0.1$ during January and February 2000. Territorial aggressiveness was found to be independent of month. Males that scored 5 to 8 for aggressiveness during the first half of the breeding season tended to become more complacent during the second half of the breeding season. The most aggressive males exhibited extreme territorial aggressiveness throughout the breeding season and tended to guard the nest during the day, especially during periods when eggs were collected and when there was human activity near the camps.
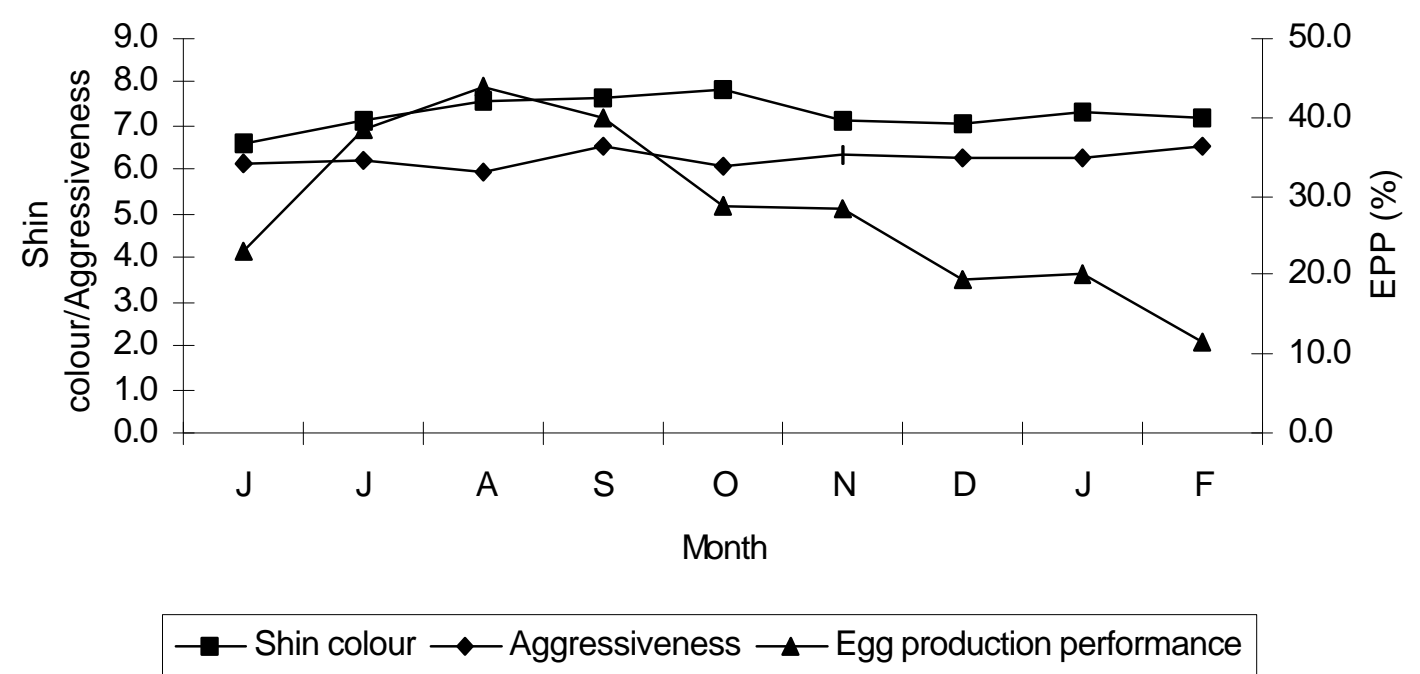

Figure 2 Mean shin colour, territorial aggressiveness and egg production performance during the breeding season.

Repeatability of shin colour, territorial aggressiveness and monthly egg production for individual pairs were $0.31 \pm 0.04,0.35 \pm 0.04$ and $0.31 \pm 0.04$, respectively. Phenotypic correlation of monthly scores for shin colour and territorial aggression with female egg production were 0.20 and $0.26(n=136)$, respectively. When monthly shin colour and territorial aggression scores were averaged for the entire breeding season, phenotypic correlation with total egg production was found to be 0.21 for shin colour and 0.29 for territorial aggressiveness.

\section{Conclusion}

It is possible that the territorial aggressiveness in ostrich males elicit a physiological response in ostrich females, which in turn initiate ovulation and subsequent egg production, possibly through the action of the respective hormones involved in the ovulation cycle of ostrich females. 